\title{
Use of a composite electrode modified with magnetic particles for electroanalysis of azo dye removed from dyed hair strands
}

\author{
Gláucia Tinoco Corrêa ${ }^{a}$, Auro Atsuchi Tanaka ${ }^{\mathrm{b}}$, Maria Isabel Pividori ${ }^{\mathrm{c}}$, Maria Valnice Boldrin Zanoni ${ }^{\mathrm{a}, *}$ \\ a Institute of Chemistry, São Paulo State University (UNESP), Rua Francisco Degni, 55, 14800-900 Araraquara, SP, Brazil \\ b Department of Chemistry, Federal University of Maranhão, Avenida dos Portugueses, 1966, Bacanga, 65080-805 São Luís, MA, Brazil \\ c Sensors and Biosensors Group, Autonomous University of Barcelona, Bellaterra, Catalonia, Spain
}

\section{A R T I C L E I N F O}

\section{Article history:}

Received 27 April 2016

Received in revised form 25 July 2016

Accepted 26 September 2016

Available online 28 September 2016

\section{Keywords:}

Hair dye

Hair dye analysis

Magnetic nanoparticles of $\mathrm{Fe}_{2} \mathrm{O}_{3}$

Magnetic composite electrode

Electroanalysis of dye from hair strands

Basic Brown 16 dye

\begin{abstract}
A B S T R A C T
The analysis of dyes in hair samples can provide useful information for forensic purposes. The present work describes a novel method for the extraction of dye from a hair sample and its determination using a composite electrode to pre-concentrate carboxyl-functionalyzed magnetic nanoparticles (CFMP) employed to collect the dye in solution, hence increasing the sensitivity of the analysis. The Basic Brown 16 dye, which is widely used in temporary hair dying, was chosen as a model compound. After $15 \mathrm{~s}$ of reaction between $1.5 \times 10^{-5} \mathrm{~mol} \mathrm{~L}^{-1}$ of dye and $0.1 \mathrm{mg} \mathrm{mL}^{-1}$ of carboxyl-functionalyzed magnetic nanoparticles in phosphate buffer electrolyte at $\mathrm{pH} 7.0$, the derivative dye was collected during $40 \mathrm{~s}$ at the graphite-epoxy composite electrode and then transferred to a new solution of phosphate buffer at $\mathrm{pH}$ 7.0. The dye presented a peak current at a potential of $0.42 \mathrm{~V}$ that was almost 400 times higher than without the preconcentration step, suggesting that the dye was pre-accumulated due to strong magnetic interaction with the composite electrode. Under optimized conditions, the analytical curve constructed using square wave voltammetry was linear for BB16 dye concentrations between $1.00 \times 10^{-7}$ and $1.00 \times 10^{-6} \mathrm{~mol} \mathrm{~L}^{-1}$. The limits of detection and quantification were $1.01 \times 10^{-8}$ and $2.37 \times 10^{-8} \mathrm{~mol} \mathrm{~L}^{-1}$, respectively. The proposed method was successfully applied in the determination of BB16 dye extracted from a dyed hair strand sample by alkaline digestion.
\end{abstract}

(C) 2016 Elsevier B.V. All rights reserved.

\section{Introduction}

The use of hair analysis is widely accepted in forensic toxicology [15]. Its application for detection of drugs of abuse is well documented, and several analytical methods can be employed to identify drug abusers [6-13]. Hair analysis can also provide important information about a person by determining the chemical makeup of the hair or by extracting DNA from the hair follicle [14-15], enabling determination of hair color, ethnic origin, presence of dye, and hairstyle, hence helping investigators to understand the basic features of a suspect. This kind of examination is typically conducted by comparing the sample with known hairs.

The literature reports several analytical methods for the determination of hair dyes in commercial formulations or in wastewater, using chromatographic [16-30] or electroanalytical methods [31-33]. However, although determination of synthetic colorants extracted from hair can be useful in many ways, the analyses require low detection limits and the literature is lacking in suitable techniques for this purpose.

\footnotetext{
* Corresponding author.
}

The use of magnetic nanoparticles (MNPs) as modifiers in the construction of electrochemical sensors has been demonstrated to provide low levels of detection for different analytes [34-38]. Magnetic nanoparticles such as iron oxides have the special ability to move under the influence of an external magnetic field. Typically, these non-porous and highly stable superparamagnetic nanoparticles (such as magnetite) are composed of a set of superparamagnetic grains that can be magnetized in the presence of a magnetic field, with alignment of the poles in the direction of the external field. This mechanism can be used to preconcentrate analytes of interest that are incorporated in these nanoparticles. Preconcentration using magnetic nanoparticles has been shown to provide high sensitivity, compared to traditional methods [39], with increased signal/noise ratio, reduced response time, and increased stability.

The present work describes the use of magnetic nanoparticles coated with carboxyl groups as a tool for dye preconcentration. Prior to the detection step, the use of modified nanoparticles enables extraction and preconcentration of the analyte of interest present in a complex sample, hence increasing the sensitivity of the analytical method. The aim was to combine the high efficiency of preconcentration using magnetic nanoparticles and the selectivity of electrochemical sensors, in order to obtain a sensitive and selective analytical method for the determination of dye extracted from hair. The widely used Basic Brown 16 temporary 
hair dye [40] (chemical structure shown in the insert of Fig. 1) was used as a dye model.

\section{Experimental}

\subsection{Reagents and equipment}

All chemicals were analytical grade and were purchased from Merck. The Basic Brown 16 (BB16) hair dye (Arianor) was provided by LCW Dyes (São Paulo, Brazil). The magnetic nanoparticles modified with carboxylic groups (MyOne carboxylic acid) were obtained from Dynal Biotech ASA (Oslo, Norway).

All the electrochemical measurements were performed using an EcoChemie $\mu$ Autolab-2 potentiostat coupled to a computer via a GPES interface. The system employed three electrodes: an $\mathrm{Ag} / \mathrm{AgCl}$ (3.0 $\mathrm{mol} \mathrm{L}^{-1} \mathrm{KCl}$ ) reference electrode, a platinum wire auxiliary electrode, and a magnetic composite working electrode with an area of $0.04 \mathrm{~cm}^{2}$. The working electrode was constructed using graphite powder and epoxy resin containing a magnet bar, as described previously [41].

Spectrophotometric measurements were carried out in the spectral range from 200 to $800 \mathrm{~nm}$, using a Hewlett Packard Model 8453 spectrophotometer equipped with a $1.0 \mathrm{~cm}$ optical path length quartz cuvette (Hellma Analytics).

Analysis of Basic Brown 16 dye and products after extraction was performed by high performance liquid chromatography/mass spectrometry (LC-ESI-MS/MS), using an Agilent Technologies Model 1200 HPLC coupled to a Model 3200 QTRAP linear ion trap quadrupole mass spectrometer. Separation was achieved using either a Phenomenex Kinetex PFP column $(150 \times 4.6 \mathrm{~mm} ; 5 \mu \mathrm{m})$ or an Agilent XDB C18 column $(150 \times 4.6 \mathrm{~mm} ; 5 \mu \mathrm{m})$. Elution of the sample was performed in isocratic mode, using a mixed mobile phase of $0.1 \%$ formic acid in water (A) and acetonitrile (B), at a flow rate of $1 \mathrm{~mL} \mathrm{~min}^{-1}$. The injection volume was $20 \mu \mathrm{L}$ and the column temperature was $40{ }^{\circ} \mathrm{C}$. The ion source was operated at $600^{\circ} \mathrm{C}$, with the following ionization conditions: IS $=5000 \mathrm{~V}$; CUR $=20$ psi; $\mathrm{Gas}_{1}=50 \mathrm{psi} ; \mathrm{Gas}_{2}=50$ psi.

\subsection{Procedures}

\subsubsection{Electroanalytical behavior}

The dye was captured by the magnetic carboxylate nanoparticles by mixing $1.5 \times 10^{-5} \mathrm{~mol} \mathrm{~L}^{-1}$ dye solution with $0.1 \mathrm{mg} \mathrm{mL}^{-1}$ of the nanoparticles in phosphate electrolyte ( $\mathrm{pH} 7$ ) during $40 \mathrm{~s}$. The pre-cleaned magnetic composite electrode was then immersed in this solution and the nanoparticles were pre-concentrated on the surface of the electrode

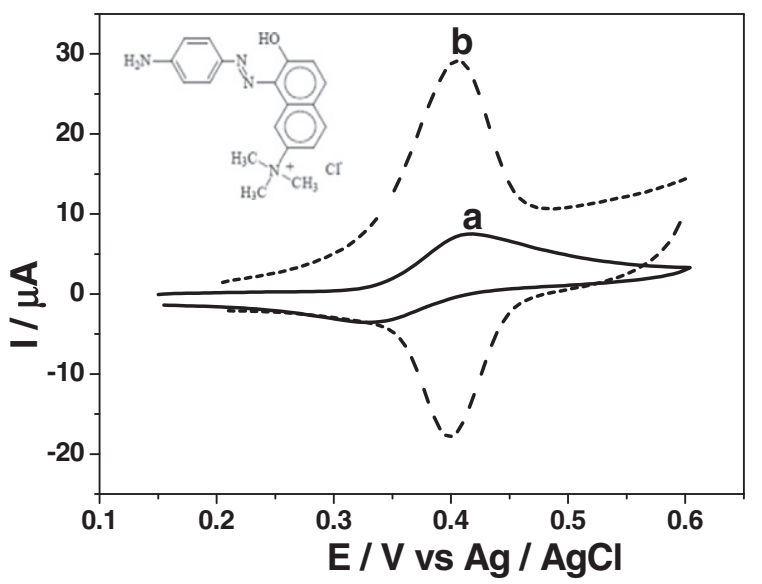

Fig. 1. Cyclic voltammograms obtained for oxidation of $3.0 \times 10^{-5} \mathrm{~mol} \mathrm{~L}^{-1} \mathrm{BB} 16$ dye at the magnetic graphite composite electrode, before (a) and after (b) $40 \mathrm{~s}$ of preconcentration in $\mathrm{pH} 7$ phosphate buffer containing $0.1 \mathrm{mg} \mathrm{mL}^{-1}$ of carboxyl-functionalyzed magnetic nanoparticles (CFMP). $\nu=100 \mathrm{mV} \mathrm{s}^{-1}$. Insert: Chemical structure of Basic Brown 16 dye. during a specified time. After the pre-concentration, the electrode was transferred to the electrochemical cell containing B-R buffer ( $\mathrm{pH} \mathrm{7)}$, and electrochemical measurements were performed with recording of both cyclic and square wave voltammograms.

\subsubsection{Dye extraction from dyed hair samples}

Human hair was dyed with BB16 as recommended in the commercial formulation instructions (LCW Dyes). The hair dyeing process was divided into 4 stages: (a) preparation of the dye; (b) application of the product to the hair and leaving to act for $40 \mathrm{~min}$; (c) rinsing the hair with water until complete removal of the unfixed dye; (d) rinsing, shampooing, and conditioning of the dyed hair. The wash water was collected in $2 \mathrm{~L}$ glass bottles, and after a further four stages of rinsing, samples were stored in vials in a freezer at $-5{ }^{\circ} \mathrm{C}$. The final stage was performed five times, with washing of the hair at predetermined times on different days. In each case, the untreated water was collected for chromatographic analysis, as described by APHA [42], using suitably washed glass flasks [43]. The samples were protected from light during transportation and were stored under refrigeration.

Afterwards, $1 \mathrm{~g}$ of previously dried hair was weighed out and incubated [44] in $2 \mathrm{~mol} \mathrm{~L}^{-1} \mathrm{NaOH}$ solution for $24 \mathrm{~h}$ at $37^{\circ} \mathrm{C}$. Following completion of the alkaline digestion of the dyed hair, the sample was neutralized with sulfuric acid. Aliquots of this solution were diluted in phosphate buffer ( $\mathrm{pH} 7$ ) and submitted to electroanalysis using the proposed method (Section 2.2.1), without any further treatment. The same solution was also analyzed by mass spectrometry.

\section{Results and discussion}

\subsection{Voltammetric behavior of the dye Basic Brown 16 dye}

Fig. 1 compares the cyclic voltammograms obtained for oxidation of $3.0 \times 10^{-5} \mathrm{~mol} \mathrm{~L}^{-1}$ BB16 at the composite electrode before (curve a) and after (curve b) $40 \mathrm{~s}$ of preconcentration in phosphate buffer (pH 7.0) containing $0.1 \mathrm{mg} \mathrm{mL}^{-1}$ of carboxyl-functionalyzed magnetic nanoparticles (CFMP). The current was four times higher in the presence of CFMP, indicating the accumulation of CFMP with dye on the electrode surface. Values of $\mathrm{I}_{\mathrm{PC}} / \mathrm{I}_{\mathrm{PA}}=0.91$ and $\mathrm{E}_{\mathrm{PA}}-\mathrm{E}_{\mathrm{PC}}=8 \mathrm{mV}$ were obtained for the modified electrode at $100 \mathrm{mV} \mathrm{s}^{-1}$, while the direct oxidation of BB16 dye showed values of $\mathrm{I}_{\mathrm{PC}} / \mathrm{I}_{\mathrm{PA}}=0.51$ and $\mathrm{E}_{\mathrm{PA}}-\mathrm{E}_{\mathrm{PC}}=61 \mathrm{mV}$. This behavior indicated that the BB16 dye was oxidized at the composite electrode, involving the transfer of approximately one electron (0.97) [45]. After preconcentration on the electrode, the oxidation of adsorbed BB16 associated with CFMP was confirmed by $\mathrm{E}_{\mathrm{PA}}-\mathrm{E}_{\mathrm{PC}}$ close to zero. In addition, the oxidation process involving BB16 dye in its derivatized form was more reversible than without modification, with the original dye remaining on the electrode surface. The signal was recovered when the electrode was washed successively with acetone and water.

In order to confirm the reaction between BB16 and the CFMP nanoparticles, UV-Vis spectra were recorded after $40 \mathrm{~s}$ of reaction using $3.0 \times 10^{-5} \mathrm{~mol} \mathrm{~L}^{-1} \mathrm{BB} 16$ and $0.1 \mathrm{mg} \mathrm{mL}^{-1}$ carboxyl-functionalyzed magnetic nanoparticles, in $\mathrm{pH} 7$ phosphate buffer (Fig. $2 \mathrm{x}$ ). In order to confirm the presence of magnetic nanoparticles, comparison was made with nanoparticles modified with tosyl groups. Although the spectrum for BB16 dye was similar to that obtained using the tosylmodified nanoparticles (Fig. $2 x$ ), there was a $60 \%$ decrease in absorbance after reaction with the carboxylic group, indicating that the dye interacted with CFMP. This phenomenon can be explained by the electrostatic interaction from carboxylate on the nanoparticles ( $\mathrm{pka}=$ 4.74) and the secondary amine group in the Basic Brown 16 dye that is positively charged (chemical structure in Fig. 1). Fig. 2y compares the infrared spectra recorded from 4000 to $400 \mathrm{~cm}^{-1}$ for the magnetic nanoparticle modified by carboxylate group before (curve a) and after reaction with the Basic Brown 16 dye (b) and for the pure Basic Brown 16 dye (c). It is possible to notice that the two sharp absorption bands at 3318 and $3190 \mathrm{~cm}^{-1}$ attributed to the stretch $\mathrm{N}-\mathrm{H}$ present as 

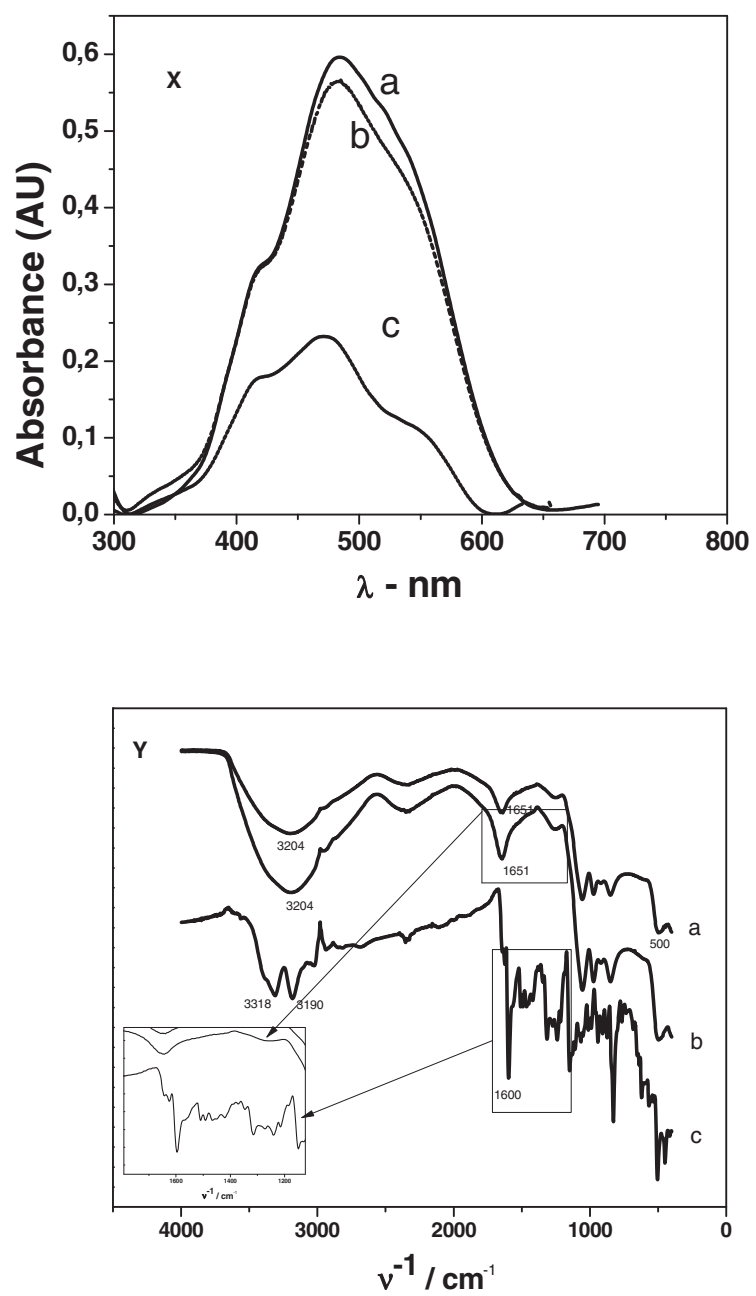

Fig. 2. Comparison of $(\mathrm{X}) \mathrm{UV}-\mathrm{Vis}$ spectra obtained for $1.5 \times 10^{-5} \mathrm{~mol} \mathrm{~L}^{-1} \mathrm{BB} 16$ dye in $\mathrm{pH} 7$ phosphate buffer, before (a) and after $40 \mathrm{~s}$ reaction with $0.1 \mathrm{mg} \mathrm{mL}^{-1}$ carboxylfunctionalyzed magnetic nanoparticles (c) and tosyl-modified magnetic nanoparticles (b). (Y) Infrared spectra in the range $4000-400 \mathrm{~cm}^{-1}$, corresponding to the magnetic nanoparticle with the Basic Brown 16 dye (a), magnetic nanoparticle (b) and Basic Brown 16 dye (c).

secondary amine in the Basic Brown 16 are substituted for a broad and intense band at $3204 \mathrm{~cm}^{-1}$ attributed to the absorption of axial deformation $\mathrm{OH}$ in the carboxylic acids. In addition, the intense absorption band at $1600 \mathrm{~cm}^{-1}$ corresponding to the symmetrical angular deformation in the $\mathrm{N}-\mathrm{H}$ plane of the dye is substituted for defined band at $1651 \mathrm{~cm}^{-1}$, which comes from the asymmetric axial deformation of carboxylate ion in the magnetic nanoparticles, confirming that the interaction between dye and modified nanoparticles occurs due strong interaction between carboxylate ion at CFMP and the amine group in the BB16 dye.

The influence of nanoparticle concentration on the collection of BB16 dye was investigated by measuring the anodic peak current obtained for $5 \times 10^{-5} \mathrm{~mol} \mathrm{~L}^{-1}$ of dye in $\mathrm{pH} 7$ phosphate buffer containing $0.05-0.20 \mathrm{mg} \mathrm{mL}^{-1}$ of CFMP. The peak current increased for CFMP concentrations from 0 to $0.08 \mathrm{mg} \mathrm{mL}^{-1}$, with maximum preconcentration obtained from 0.10 to $0.20 \mathrm{mg} \mathrm{mL}^{-1}$. Further studies were carried out using $0.10 \mathrm{mg} \mathrm{mL}^{-1}$ CFMP.

Fig. 3 illustrates the influence of reaction time $(0-50 \mathrm{~s})$ on the preconcentration of BB16 dye. The experiments were carried out recording cyclic voltammograms for electrodes immersed in a solution containing $5 \times 10^{-5} \mathrm{~mol} \mathrm{~L}^{-1}$ of dye in $\mathrm{pH} 7$ phosphate buffer with $0.10 \mathrm{mg} \mathrm{mL}^{-1}$ of CFMP. After preaccumulation for a specified time, the electrode was transferred to a new solution consisting only of


Fig. 3. Cyclic voltammograms (A) recorded for oxidation of $5 \times 10^{-5} \mathrm{~mol} \mathrm{~L}^{-1}$ dye $+0.10 \mathrm{mg} \mathrm{mL}^{-1}$ CFMP in pH 7 phosphate buffer, using preaccumulation for (a) $10 \mathrm{~s}$, (b) $20 \mathrm{~s}$, (c) $30 \mathrm{~s}$, (d) $40 \mathrm{~s}$, and (e) $50 \mathrm{~s}$, followed by transfer of the electrode to a new solution containing $\mathrm{pH} 7$ phosphate buffer alone. (B) Effect of accumulation time of BB16 + CFMP at the magnetic graphite composite electrode in $\mathrm{pH} 7$ phosphate buffer. $v=0.05 \mathrm{~V} \mathrm{~s}^{-1}$.

pH 7 phosphate buffer. The pair of peaks corresponding to BB16 oxidation/reduction increased for times from 10 to $40 \mathrm{~s}$ (Fig. 3B), indicating that the dye + CFMP was accumulated on the electrode surface. Maximum peak intensity was observed after $40 \mathrm{~s}$, suggesting saturation of dye + CFMP deposited on the magnetic composite electrode. Further studies were carried out using 40 s exposures to the solution containing dye + CFMP, followed by transfer to a fresh electrolyte solution.

Cyclic voltammograms recorded from 10 to $100 \mathrm{mV} \mathrm{s}^{-1}$ for $1.5 \times 10^{-5} \mathrm{~mol} \mathrm{~L}^{-1} \mathrm{BB} 16$ in $\mathrm{pH} 7$ phosphate buffer, after pre-concentration for $40 \mathrm{~s}$, showed progressively larger anodic and cathodic peaks (not shown). A linear relationship was obtained between the anodic peak current and the scan rate, described by the equation: $\mathrm{I}(\mu \mathrm{A})=$ $5.5+0.36 \mathrm{mV} \mathrm{s}^{-1}(r=0.9987, n=7)$. This behavior indicated that oxidation of the dye at the magnetic electrode was controlled by adsorption [46]. It was also noted that for scan rates of between 10 and $50 \mathrm{mV} \mathrm{s}^{-1}$, the values obtained were $\mathrm{I}_{\mathrm{PA}} / \mathrm{I}_{\mathrm{PC}}=1$ and $\mathrm{E}_{\mathrm{PA}}-\mathrm{E}_{\mathrm{PC}}=0 \mathrm{mV}$. This behavior is typical of a reversible process involving the adsorption of oxidized and reduced forms on an electrode surface [46].

The effect of $\mathrm{pH}$ on the anodic peak current and peak potential obtained from the cyclic voltammograms acquired at $50 \mathrm{mV} \mathrm{s}^{-1}$ was investigated for $4 \times 10^{-5} \mathrm{~mol} \mathrm{~L}^{-1}$ BB16 in phosphate buffer ( $\mathrm{pH} 3-9$ ), in the absence and presence of magnetic nanoparticles. The peak potential shifted to less positive potentials with increasing $\mathrm{pH}$, following a linear relationship: Ep $(\mathrm{V})=0.70-0.050 \mathrm{pH}$ (Fig. 4, curve A). In addition, there was a gradual increase in current from $\mathrm{pH}>3.0$ up to $\mathrm{pH} 7.0$ (Fig. 4, curve B), with the values remaining constant at higher $\mathrm{pH}$. This behavior confirmed that the dye + CFMP was preconcentrated at the composite electrode due to magnetic interaction, reaching a maximum at $\mathrm{pH}$ 7. The slope of $-50 \mathrm{mV} \mathrm{pH}^{-1}$ obtained from $\Delta \mathrm{E} / \Delta \mathrm{pH}$ suggested 


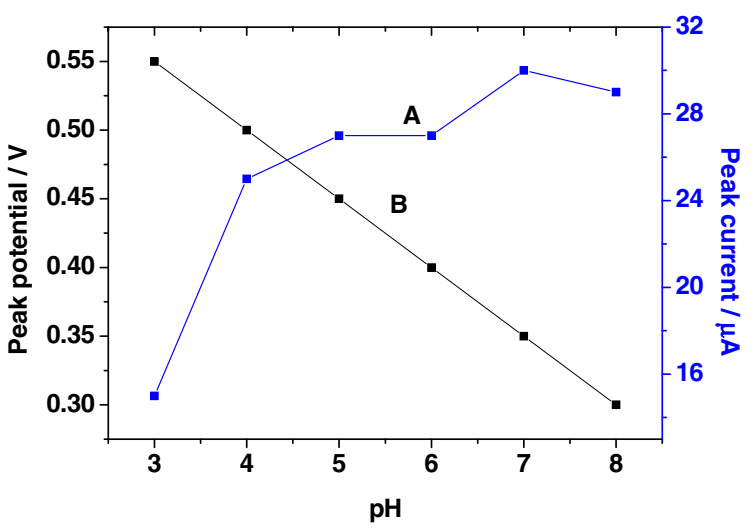

Fig. 4. Influence of $\mathrm{pH}$ on anodic peak current (A) and anodic peak potential (B), obtained from cyclic voltammograms recorded for oxidation of $4 \times 10^{-5} \mathrm{~mol} \mathrm{~L}^{-1} \mathrm{BB} 16+$ CFMP in phosphate buffer

that a one electron/one proton transfer mechanism occurred in this $\mathrm{pH}$ range. Considering that the process involved the transfer of one electron, according to the equation $\Delta \mathrm{E} / \Delta \mathrm{pH}=(59.1 \mathrm{mV} / \mathrm{n})^{*} \mathrm{mH}^{+}(n=1)$, and using the slope obtained, it appeared that the number of protons $\left(\mathrm{mH}^{+}\right)$transferred was one [47-48]. These results indicated that the hydroxyl group close to the azo group in the BB16 dye (see Fig. 1 insert) was oxidized to the quinone radical at around $+0.40 \mathrm{~V}$, after previous interaction with the CFMP on the magnetic electrode [47]. Therefore, $\mathrm{pH} 7$ was selected in the subsequent analyses.

In order to achieve detection of BB16 dye at low levels, the use of square wave voltammetry (SWV) was evaluated, with monitoring of the oxidation of $4.0 \times 10^{-5} \mathrm{~mol} \mathrm{~L}^{-1}$ of BB16 dye in phosphate buffer solution ( $\mathrm{pH} 7.0$ ) after accumulation for $40 \mathrm{~s}$ (Fig. 5). A peak increase of approximately $400 \%$ was obtained, relative to linear scanning voltammetry, so these conditions were used for quantification of the dye. The peak current obtained was dependent on various instrumental parameters of the SWV technique, such as square wave amplitude, square wave frequency, and step height. The experimental parameters evaluated were frequency, $f$ (from 10 to $300 \mathrm{~Hz}$ ), scan increment, $\Delta E$ s (from 1 to $15 \mathrm{mV}$ ), and pulse amplitude, Esw (from 10 to $150 \mathrm{mV}$ ). The optimum voltammetric signal was obtained for a frequency of $30 \mathrm{~Hz}$, pulse amplitude of $50 \mathrm{mV}$, and $\Delta E \mathrm{~s}$ of $2 \mathrm{mV}$, which provided better voltammogram definition as well as higher peak currents.

Fig. 6 illustrates square wave voltammograms recorded for between $1.0 \times 10^{-7}$ and $9.0 \times 10^{-7} \mathrm{~mol} \mathrm{~L}^{-1} \mathrm{BB} 16$ dye derivatized with

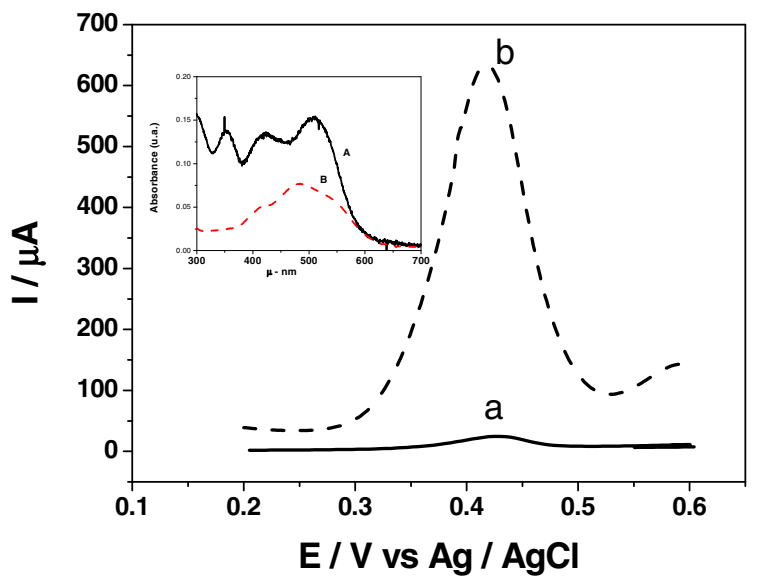

Fig. 5. Linear scanning voltammograms (a) and square wave voltammograms (b) obtained for $4.0 \times 10^{-5} \mathrm{~mol} \mathrm{~L}^{-1} \mathrm{BB} 16$ in $\mathrm{pH} 7$ phosphate buffer after accumulation for $15 \mathrm{~s}$ at the magnetic graphite composite electrode. Insert: UV-Vis spectra for $5 \times 10^{-5} \mathrm{~mol} \mathrm{~L}^{-1} \mathrm{BB} 16$ in $2 \mathrm{~mol} \mathrm{~L}^{-1} \mathrm{NaOH}$ (30 min) (curve A), and after neutralizing and adjusting to $\mathrm{pH} 7$ (curve $\mathrm{B}$ ).

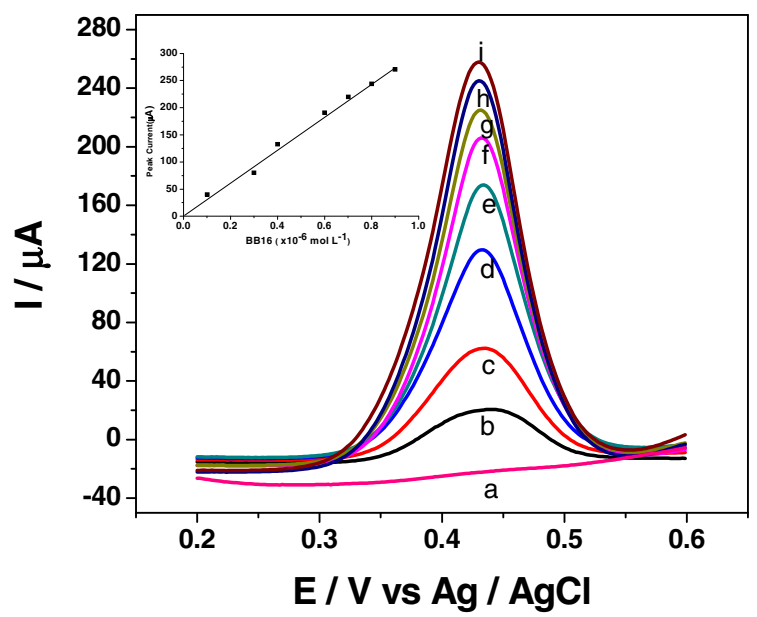

Fig. 6. Square wave voltammograms recorded for $1.0 \times 10^{-7}$ (b), $2 \times 10^{-7}$ (c), $4 \times 10^{-7}$ (d), $5 \times 10^{-7}$ (e), $6 \times 10^{-7}(\mathrm{f}), 7 \times 10^{-7}(\mathrm{~g}), 8 \times 10^{-7}(\mathrm{~h})$, and $9 \times 10^{-7} \mathrm{~mol} \mathrm{~L}^{-1}$ (i) of BB16 dye derivatized with $0.1 \mathrm{mg} \mathrm{mL}^{-1}$ CFMP in $\mathrm{pH} 7$ phosphate buffer, using preconcentration for $40 \mathrm{~s}$ at the composite electrode. (a) Voltammogram for $\mathrm{pH} 7$ phosphate buffer; $\mathrm{f}=30 \mathrm{~s}^{-1} ; \mathrm{a}=50 \mathrm{mV} ; \Delta \mathrm{Es}=2 \mathrm{mV}$. Insert: analytical curve.

$0.1 \mathrm{mg} \mathrm{mL}^{-1} \mathrm{CFMP}$, using $40 \mathrm{~s}$ preconcentration at the composite electrode. The linear range was described by the equation: - Ipc $(\mu \mathrm{A})=-1.230+183.6^{*} \mathrm{C}_{\mathrm{BB} 16}\left(\mu \mathrm{mol} \mathrm{L}^{-1}\right)(r=0.996, n=7)$. The limits of detection and determination were $1.01 \times 10^{-8}$ and $2.37 \times 10^{-8} \mathrm{~mol} \mathrm{~L}^{-1}$, respectively. The repeatability of the proposed sensor, evaluated in terms of the relative standard deviation, was $3.79 \%$ for ten SWV experiments, indicating that the technique provided satisfactory reproducibility.

The proposed method based on BB16 + CFMP was applied using tap water samples spiked with $7.5 \times 10^{-7} \mathrm{~mol} \mathrm{~L}^{-1} \mathrm{BB} 16$ and $0.10 \mathrm{mg} \mathrm{mL}^{-1}$ CFMP. Recoveries were performed in triplicate using the standard additions method, with $40 \mathrm{~s}$ of pre-reaction and transfer of the electrode to a solution containing $10 \mathrm{~mL}$ of $\mathrm{pH} 7$ phosphate buffer. For all the samples, the recovery values were in the range $99.1-102.4 \%$.

In order to verify the selectivity of the proposed method the interference of Basic Red 51 dye (BR51), a common temporary hair dye usually commercialized in a formulation containing BB16 dye. In a solution containing $5.0 \times 10^{-7} \mathrm{~mol} \mathrm{~L}^{-1}$ BB51 dye was added BB16 dye in the

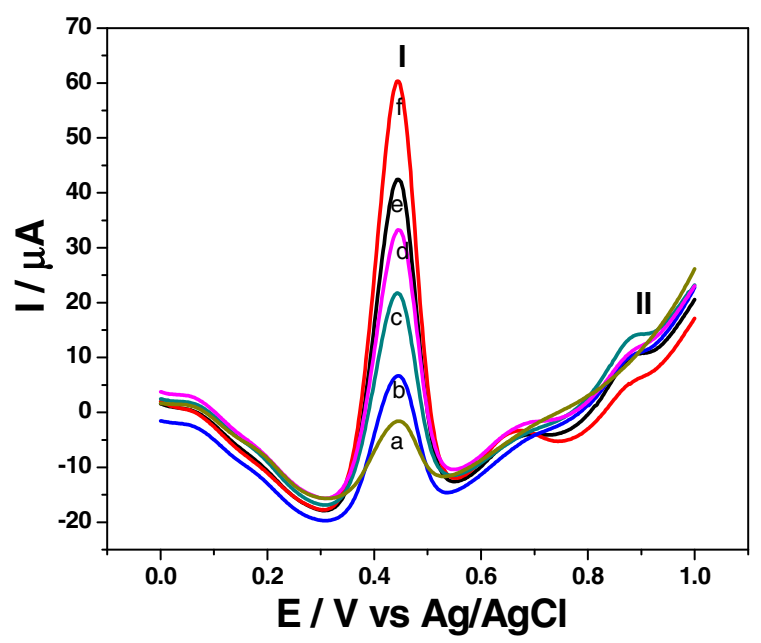

Fig. 7. Square wave voltammograms obtained for oxidation of $5.0 \times 10^{-7}$ Basic Red 51 in the presence of Basic Brown 16 dye (Peak I) at concentrations of (a) $5.0 \times 10^{-7}$, (b) $7.5 \times 10^{-7}$, (c) $1.0 \times 10^{-6}$, (d) $1.25 \times 10^{-6}$, (e) $1.5 \times 10^{-6}$ and (f) $1.75 \times 10^{-6} \mathrm{~mol} \mathrm{~L}^{-1}$ at composite electrode in phosphate buffer solution $(\mathrm{pH} 7)$ using metal nanoparticles CFMP. 
concentration range from $5.0 \times 10^{-7}$ to $2.0 \times 10^{-6} \mathrm{~mol} \mathrm{~L}^{-1}$. Fig. 7 shows the square wave voltammograms recorded after preconcentration of $15 \mathrm{~s}$. Although BR51 presented a small peak at $-0.87 \mathrm{~V}$, there is no effect on the peak current of BB16 dye at $0.45 \mathrm{~V}$, which increases successively with the addition of BB16 dye while the current peak attributed to dye BR51 remains constant. A linear relationship was obtained following the equation: I / $(\mu \mathrm{A})=-2.33 \times 10^{-6}+49.68 \times 10^{-6}[\mathrm{BB} 16] / \mathrm{mol} \mathrm{L}^{-1} ; r=0.9882$ and $n=5$. The results indicated that the voltammetric sensor can be used to analyze the BB16 dye even in the presence of BR51 dye, bearing azo groups in the molecule.

\subsection{Analytical application of the proposed method}

\subsubsection{Analysis of wastewater from dyed hair}

The applicability of the proposed method was tested using water from the washing of hair previously dyed with BB16. Portions $(1 \mathrm{~g})$ of hair dyed with BB16 according to the instructions of the commercial formulation were washed with water that was collected and analyzed to determine the stability of the dye (not shown). Aliquots $(1 \mathrm{~mL})$ of the washing water were analyzed using the proposed method. The use of square wave voltammetry resulted in well-defined peaks and an excellent linear relationship after standard additions of BB16 in the concentration range from $1.08 \times 10^{-7}$ to $1.34 \times 10^{-6} \mathrm{~mol} \mathrm{~L}^{-1}$. The results showed that $0.045 \mathrm{mg}$ of the dye was leached from $1 \mathrm{~g}$ of dyed hair during the first washing, corresponding to a loss of $1.26 \%$ of the dye used to color the hair.

\subsubsection{Analysis of the dye extracted from hair}

Finally, the proposed method was tested in the analysis of dye extracted from dyed hair strands, following the methodology described in the Experimental section. Portions ( $1 \mathrm{~g}$ ) of dyed hair were washed, dried, and subjected to alkaline digestion, as described previously. Different methodologies were tested for the removal of the dye from the hair strands, and the best performance was achieved using alkaline digestion [44]. The techniques were evaluated by recording UV-Vis spectra and mass spectra for the dye, before and after treatment with $2 \mathrm{~mol} \mathrm{~L}^{-1} \mathrm{NaOH}$.

The insert of Fig. 5 shows a comparison of the UV-Vis spectra for $5 \times 10^{-5} \mathrm{~mol} \mathrm{~L}^{-1} \mathrm{BB} 16$ in $2 \mathrm{~mol} \mathrm{~L}^{-1} \mathrm{NaOH}$ (30 min) (curve A), and after neutralizing and adjusting to $\mathrm{pH} 7$ (curve $\mathrm{B}$ ). A typical UV-Vis spectrum was obtained for BB16 dye at $\mathrm{pH} 7.0$, showing main bands with maximum absorption wavelengths at 495 and $425 \mathrm{~nm}$, attributed to the azo group of BB16 ${ }^{45}$. For the dye in alkaline medium, the UV-Vis spectrum showed four bands, at 509, 416, 353, and $249 \mathrm{~nm}$, due to temporary hydrolysis (curve B, insert of Fig. 5). However, the UV-Vis spectra were recovered when the alkaline solution was once again neutralized to $\mathrm{pH} 7$, and were very similar to the spectrum obtained previously (Fig. 2, curve A). These results showed that in alkaline solution, the dye did not undergo any irreversible changes in its chemical structure, and that the process could be used during the extraction phase in an alkaline medium.

Further LC-ESI-MS/MS measurements of BB16 were carried out before and after treatment with alkaline solution. Fig. 8 presents the chromatograms obtained for the dye in water containing $0.1 \%$ of formic acid and acetonitrile, using the selected reaction monitoring (SRM) transitions and the optimized MS parameters. The original dye (curve 2, Fig. 8) showed a well-defined peak at a retention time of $5.80 \mathrm{~min}$, attributed to the $[\mathrm{M}+\mathrm{H}]^{+}$ion with $m / z=321$. The fragmentation of this ion produced the expected product ions with higher abundance. Curve 1 (Fig. 7) shows the LC-MS-MS chromatogram for BB16 submitted to treatment with $\mathrm{NaOH}$ for $120 \mathrm{~min}$. A peak $(\mathrm{m} / \mathrm{z}=321)$ was observed at a retention time of $5.80 \mathrm{~min}$, indicating that treatment of the dye with sodium hydroxide did not cause any modification of its chemical structure. Hence, the developed procedure was adopted for extraction

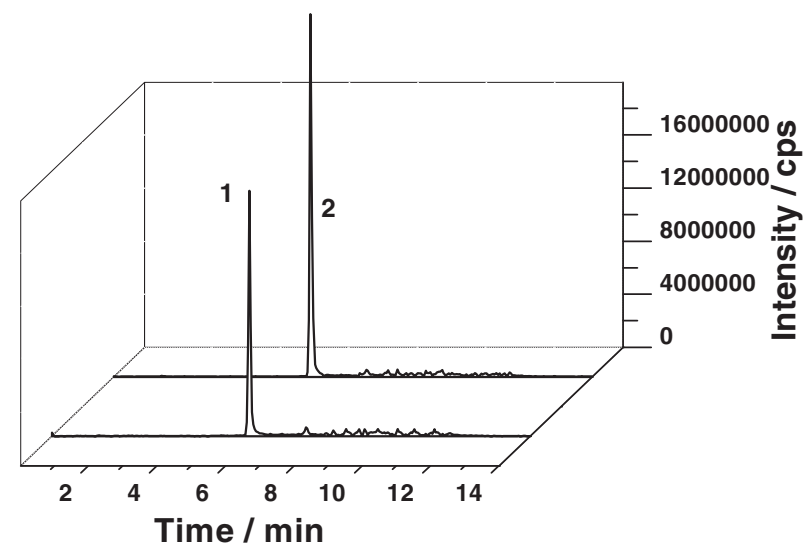

Fig. 8. LC-MS-MS chromatograms obtained for BB16, before (2) and after (1) 120 min in sodium hydroxide followed by neutralization to $\mathrm{pH} 7.0$.

of the dye from hair followed by analysis using the electroanalytical method.

Square wave voltammograms were obtained for $50 \mu \mathrm{L}$ aliquots of extract (described in the experimental section) transferred directly to $1 \mathrm{~mL}$ of pH 7 phosphate buffer containing $0.1 \mathrm{mg} \mathrm{mL}^{-1}$ of magnetic nanoparticles. After pre-accumulation for $40 \mathrm{~s}$, the composite electrode was transferred to $10.0 \mathrm{~mL}$ of $\mathrm{pH} 7$ phosphate buffer containing $0.1 \mathrm{mg} \mathrm{mL}^{-1}$ of magnetic nanoparticles. Square wave voltammograms were then obtained using standard additions of BB16 at concentrations from $7.5 \times 10^{-7}$ to $1.5 \times 10^{-6} \mathrm{~mol} \mathrm{~L}^{-1}$, without any pretreatment. An excellent linear relationship was obtained, and the results indicated that $0.017 \mathrm{mg}$ of the dye was present, corresponding to $3.51 \mathrm{mg}$ of dye per $1 \mathrm{~g}$ of hair.

\section{Conclusions}

A simple and reliable electroanalytical method is proposed based on the interaction of carboxyl-functionalyzed magnetic nanoparticles (CFMP) with Basic Brown 16 dye, followed by preaccumulation on a graphite-epoxy composite electrode. The derivatized dye presented a well-defined peak attributed to hydroxyl oxidation. Square wave voltammetry was used to construct an analytical curve for BB16 concentrations from $1.0 \times 10^{-7}$ to $1.0 \times 10^{-6} \mathrm{~mol} \mathrm{~L}^{-1}$ after reaction in the presence of $0.1 \mathrm{mg} \mathrm{mL}^{-1}$ of CFMP and further preconcentration for $40 \mathrm{~s}$ at the composite electrode. The azo dye was extracted from dyed hair strands using $2 \mathrm{~mol} \mathrm{~L}^{-1}$ sodium hydroxide, without any irreversible changes in its chemical structure, as shown by UV-Vis spectra and LC-MS/MS measurements. The proposed method is inexpensive and environmentally friendly, and enables the detection of BB16 dye at low levels in dyed hair extracts.

\section{Acknowledgments}

The authors gratefully acknowledge the financial support provided by FAPESP (processes \#2013/21542-6 and \#2008/10449-7), CAPES, and CNPq.

\section{References}

[1] F.R.A. Neto, M.A.S. Marques, H.M.G. Pereira, Controle de dopagem no esporte: aspectos químicos e farmacológicos que afetam a detecção de drogas no cabelo, Rev. Bras. Cienc. Farm. 38 (2002) 259-271.

[2] M.R. Moeller, Hair analysis as evidence in forensic cases, Ther. Drug Monit. 18 (1996) 444-449.

[3] P. Kintz, V. Cirimele, V. Dumestre-Toulet, B. Ludes, Doping control for nandrolone using hair analysis, J. Pharm. Biomed. Anal. 24 (2001) 1125-1130.

[4] P. Kintz, Clinical applications of hair analysis, in: P. Kintz (Ed.), Drug Testing in Hair CRC Press, Boca Raton 1996, pp. 267-277. 
[5] G. Sherer, U. Wachter, S.A. Wudy, Determination of testosterone in human hair by gas chromatography-selected ion monitoring mass spectrometry, Analyst 123 (1998) 2661-2663.

[6] W.A. Baumgartner, P.F. Jones, C.T. Black, W.H. Blahd, Radioimmunoassay of cocaine in hair: concise communication, J. Nucl. Med. 23 (1982) 779-790.

[7] M.A. Balbino, E.N. Oiye, M.F.M. Ribeiro, J.W. Cruz Júnior, I.C. Eleotério, A.J. Ipólito M.F. Oliveira, Use of screen-printed electrodes for quantification of cocaine and $\Delta^{9}$-THC: adaptions to portable systems for forensic purposes, J. Solid State Electrochem. 1-9 (2016).

[8] B.D. Sabino, W. Romão, M.L. Sodré, D.N. Correa, D.B.R. Pinto, M.N. Eberlin, Analysis of cocaine and crack cocaine via thin layer chromatography coupled to easy ambient sonic-spray ionization mass spectrometry, Am. J. Anal. Chem. 2 (2011) 658-664.

[9] J.F. Kelly, K. Addanki, O. Bagasra, The non-specificity of the Duquenois-Levine field test for marijuana, Open Forensic Sci. J. 5 (2012) 4-8.

[10] D.C. Bordim, M. Messias, R. Lanaro, S.O.S. Cazenave, J.L. Costa, Forensic analysis: evaluation of interfering vegetable drugs in colorimetric tests for identifying marijuana cannabinoids (Cannabis sativa L.), Quim. Nov. 35 (2012) 2040-2043.

[11] C.A. Woolever, D.E. Starkey, H.D. Dewald, Differential pulse anodic stripping voltammetry of lead and antimony in gunshot residues, Forensic Sci. Int. 102 (1999) 45-50.

[12] A.L. Liu, J.D. Wang, W. Chen, X.U. Xia, Y.Z. Chen, X.H. Lin, Simultaneous and sensitive determination of procaine and its metabolite for pharmaceutical quality control and pharmacokinetic research by using a graphite paste electrode, J. Solid State Electrochem. 16 (2012) 1343-1351.

[13] B. Rezaei, S.J. Damiri, Development of a voltammetric procedure for assay of thebaine at a multi-walled carbon nanotubes electrode: quantification and electrochemical studies, Solid State Electron. 14 (2010) 1079-1088.

[14] P.T. Frank, R. Daniela, Aspects of matrix effects in applications of liquid chromatography-mass spectrometry to forensic and clinical toxicology - a review, Anal. Bioanal. Chem. 403 (2012) 2155-2172.

[15] W. Mitsuhiro, I. Rie, K. Naotaka, N. Kenichiro, Analytical methods for abused drugs in hair and their applications, Anal. Bioanal. Chem. 397 (2010) 1039-1067.

[16] N.A. Penner, P.N. Nesterenko, Simultaneous determination of dihydroxybenzenes, aminophenols and phenylenediamines in hair dyes by high-performance liquid chromatography on hypercross-linked polystyrene, Analyst 125 (2000) 1249-1254.

[17] S.P. Wang, H.J. Chen, Separation and determination of nitrobenzenes by micella electrokinetic chromatography and high-performance liquid chromatography, J. Chromatogr. A 979 (2002) 439-446.

[18] G. Choudhary, Gas-liquid chromatographic determination of toxic diamines in permanent hair dyes, J. Chromatogr. A 193 (1980) 277-284.

[19] H. Tokuda, Y. Kimura, S. Takano, Determination of dye intermediates in oxidative hair dyes by fused-silica capillary gas chromatography, J. Chromatogr. A 367 (1986) 345-356

[20] B. Schultz, Determination of 4-aminophenol in water by high-performance liquid chromatography with fluorescence detection, J. Chromatogr. A 299 (1984) 484-486.

[21] M.C. Gennaro, P.L. Bertolo, E. Marengo, Determination of aromatic amines at trace levels by ion interaction reagent reversed-phase high-performance liquid chromatography: analysis of hair dyes and other water-soluble dyes, J. Chromatogr. A 518 (1990) 149-156

[22] V. Andrisano, R. Gotti, A.M. Di Pietra, V. Cavrini, HPLC analysis of oxidation hair dyes in permanent hair colorants, J. Liq. Chromatogr. Relat. Technol. 17 (1994) 2919-2937.

[23] N. Goetz, P. Lasserre, P. Boré, G. Kalopissis, Percutaneous absorption of p-phenylene diamine during an actual hair dyeing procedure, Int. J. Cosmet. Sci. 10 (1988) 63-73.

[24] C. Sainthorant, P.H. Morin, M. Dreux, A. Baudry, N. Goetz, Separation of phenylenediamine, phenol and aminophenol derivatives by micellar electrokinetic chromatography. Comparison of the role of anionic and cationic surfactants, J. Chromatogr. A 717 (1995) 167-179.

[25] C.E. Lin, Y.T. Chen, T.Z. Wang, Separation of benzenediamines, benzenediols and aminophenols in oxidative hair dyes by micellar electrokinetic chromatography using cationic surfactants, J. Chromatogr. A 837 (1999) 241-252.

[26] V. Andrisano, R. Gotti, P. Roveri, V. Cavrini, Analysis of semipermanent hair dyes by HPLC with on-line post-column photochemical derivatisation, Chromatographia 44 (1997) 431-437.
[27] E. Mariani, C. Neuhoff, C. Villa, Application of high-performance liquid chromatography in the analysis of direct dyes in semipermanent hair colouring cosmetics, Int. J. Cosmet. Sci. 19 (1997) 51-63.

[28] E. Mariani, A. Bargagna, M. Longobard, S. Dorato, Application of TLC and HPTLC in the analysis of semipermanent hair dyes, Int. J. Cosmet. Sci. 16 (1994) 17-27.

[29] T.M. Lizier, M.V.B. Zanoni, Effect of ionic liquid on the determination of aromatic amines as contaminants in hair dyes by liquid chromatography coupled to electrochemical detection, Molecules 17 (2012) 7961-7979.

[30] C. Scarpi, F. Ninci, M. Centini, C. Anselmi, High-performance liquid chromatography determination of direct and temporary dyes in natural hair colourings, J. Chromatogr. A 796 (1998) 319-325.

[31] R.A. Oliveira, F.F. Hudari, J.H. Franco, M.V.B. Zanoni, Carbon nanotube-based electrochemical sensor for the determination of anthraquinone hair dyes in wastewaters, Chemosensors 3 (2015) 22-35.

[32] F.F. Hudari, L.C. Almeida, B.F. Silva, M.V.B. Zanoni, Voltammetric sensor for simultaneous determination of p-phenylenediamine and resorcinol in permanent hair dyeing and tap water by composite carbon nanotubes/chitosan modified electrode, Microchem. J. 116 (2014) 261-268.

[33] R.A. Oliveira, M.V.B. Zanoni, Highly ordered $\mathrm{TiO}_{2}$ nanotubes for electrochemical sensing of hair dye Basic Brown 17, Electroanalysis 25 (2013) 2507-2514.

[34] H. Bagheri, A. Afkhami, Y. Panahi, H. Khoshsafar, A. Shirzadmehr, Facile stripping voltammetric determination of haloperidol using a high performance magnetite/ carbon nanotube paste electrode in pharmaceutical and biological samples, Mater. Sci. Eng. C 37 (2014) 264-270.

[35] H. Yin, Y. Zhou, Q. Ma, S. Ai, Q. Chen, L. Zhu, Electrocatalytic oxidation behavior of guanosine at graphene, chitosan and $\mathrm{Fe}_{3} \mathrm{O}_{4}$ nanoparticles modified glassy carbon electrode and its determination, Talanta 82 (2010) 1193-1199.

[36] S.V. Kergaravat, L. Beltramino, N. Garnero, L. Trotta, M. Wagener, M.I. Pividori, S.R. Hernandez, Electrochemical magneto immunosensor for the detection of anti-TG2 antibody in celiac disease, Biosens. Bioelectron. 48 (2013) 203-209.

[37] S.V. Kergaravat, G.A. Gómez, S.N. Fabiano, T.I.L. Chávez, M.I. Pividori, S.R. Hernandez, Biotin determination in food supplements by an electrochemical magneto biosensor, Talanta 97 (2012) 484-490.

[38] A. Erdem, M.I. Pividori, A. Lermo, A. Bonanni, M.d. Valle, S. Alegret, Genomagnetic assay based on label-free electrochemical detection using magneto-composite electrodes, Sensors Actuators B 114 (2006) 591-598.

[39] M.S. Castilho, T. Laube, H. Yamanaka, S. Alegret, M.I. Pividori, Magneto immunoassays for plasmodium falciparum histidine-rich protein 2 related to malaria based on magnetic nanoparticles, Anal. Chem. 83 (2011) 5570-5577.

[40] R.A.G. Oliveira, M.V.B. Zanoni, G.G. Bessegato, D.P. Oliveira, G.A. Umbuzeiro, The chemistry and toxicity of hair dyes, Quim Nova 37 (2014) 1037-1046.

[41] A. Erdem, M.I. Pividori, A. Lermo, A. Bonanni, M.D. Valle, S. Alegret, Genomagnetic assay based on label-free electrochemical detection using magneto-composite electrodes, Sensors Actuators B Chem. 114 (2006) 591-598.

[42] Standard Methods for the Examination of Water and Wastewater, 20th ed. American Public Health Association, Washington, DC, 1998.

[43] US Environmental Protection Agency, Office of Water, Manual for the Certification of Laboratories Analyzing Drinking Water. Criteria and Procedures, 45268. EPA 815 B97-001, March 1997, 1997 (Cincinnati, USA).

[44] V.A. Boumba, K.S. Ziavrou, T. Vougiouklakis, Hair as a biological indicator of drug use, drug abuse or chronic exposure to environmental toxicants, Int. J. Toxicol. 25 (2006) 143-163.

[45] H. Zollinger, Color Chemistry: Synthesis, Properties and Applications of Organic Dyes and Pigments, 2nd ed. VCH Publishers, New York, 1991.

[46] A.J. Bard, L.R. Faulkner, Potential sweep methods, Electrochemical Methods: Fundamentals and Applications, 2nd ed.John Wiley, New York 2001, pp. 226-260.

[47] C.C.I. Guaratini, A.G. Fogg M.V.B. Zanoni, Assessment of the application of cathodic stripping voltammetry to the analysis of diazo reactive dyes and their hydrolysis products, Dyes Pigments 50 (2001) 211-221.

[48] J. Barek, A.G. Fogg, J.C. Moreira, M.V.B. Zanoni, J. Zima, Polarographic and voltammetric determination of selected triazine-based azo dyes with different reactive groups, Anal. Chim. Acta 320 (1996) 31-42. 